(2) Open Access Full Text Article

\title{
Comparison of selective laser trabeculoplasty (SLT) in primary open angle glaucoma and pseudoexfoliation glaucoma
}

This article was published in the following Dove Press journal:

Clinical Ophthalmology

II October 201]

Number of times this article has been viewed

\author{
Marcelo Ayala \\ Enping Chen \\ Glaucoma Department, St Erik \\ Eye Hospital, Karolinska Institutet, \\ Stockholm, Sweden
}

Background and objective: The aim of the present study was to compare intraocular pressure (IOP) reduction and inflammation after selective laser trabeculoplasty (SLT) treatment in patients suffering from primary open angle (POAG) vs pseudoexfoliative (PXFG) glaucoma.

Study design/patients and methods: Sixty patients (60 eyes) participated in the study. Glaucoma patients (POAG or PXFG) scheduled for treatment with SLT were included. Inflammation was measured with a laser flare meter (Kowa FM-500). Measurements were made before SLT and 2 hours, 1 week, and 1 month after SLT treatment. IOP was also checked at the same time intervals.

Results: Inflammation after SLT showed no significant difference between the groups $(t$-test, before: $P=0.16$; 2 hours: $P=0.14$; 1 week: $P=0.12$; and 1 month: $P=0.36$ ). IOP reduction was the same in both groups ( $t$-test, $P=0.27$ ).

Conclusion: SLT safely reduces IOP in both POAG and PXFG. Pseudoexfoliation does not seem to be a risk factor for post-laser complications.

Keywords: glaucoma, pseudoexfoliation, laser, inflammation, intraocular pressure

\section{Introduction}

Glaucoma is a progressive neuropathy localized in the optic nerve that may lead to blindness. Reducing intraocular pressure (IOP) seems to be the only treatment proven to slow progression in glaucoma. ${ }^{1}$ There are several methods to reduce IOP: pharmaceutical treatment, laser treatment, and surgery. In the Glaucoma Laser Trial Follow-up Study, after 7 years of follow-up, patients who had undergone argon laser trabeculoplasty (ALT) had lower IOP than patients on pharmaceutical treatment. ${ }^{2,3}$ However, there has been no randomized trial comparing SLT to medical treatment. SLT appears to be less costly than current medical treatment. ${ }^{4}$

Argon laser trabeculoplasty (ALT) was introduced about 35 years ago and involves the use of a blue/green argon laser (major wavelength peaks at $488 \mathrm{~nm}$ and $514 \mathrm{~nm}$ ) to treat the outer part of the trabecular meshwork and thereby improve aqueous flow and thus reduce IOP. Selective Laser Trabeculoplasty (SLT) uses a 532-nm frequency-doubled, Q-switched Nd:YAG laser that delivers a low-energy, large spot, very brief pulse to selectively target cells of the trabecular meshwork. This "milder" laser application is thought to stimulate the pigmented trabecular meshwork cells and thus facilitate improved aqueous outflow. The exact mechanism of action for reducing the IOP is not known. ${ }^{5}$

Pseudoexfoliation prevalence varies between different countries. In the US, Karger et $\mathrm{al}^{6}$ showed an annual incidence of 25.9 per 100,000 (mean age 73) and 
found an increased number with increasing age. Although pseudoexfoliation has a worldwide distribution, it appears more common in Scandinavia. Pseudoexfoliation prevalence in northern Sweden is estimated to be $23 \%$ at 66 years and $61 \%$ at 87 years. $^{7}$ Pseudoexfoliative glaucoma is estimated to account for around $50 \%$ of all glaucoma patients diagnosed in Sweden. ${ }^{8,9}$ Information regarding the influence of pseudoexfoliation on SLT results is scarce. Gracner et $\mathrm{al}^{10}$ showed no difference in SLT results (IOP reduction) comparing pseudoexfoliative and primary open angle glaucoma when ten patients were followed for 18 months. Shazly et al ${ }^{11}$ showed SLT to be safe for IOP reduction as a primary treatment in PXFG. Goldenfeld et $\mathrm{al}^{12}$ showed that after SLT in PXFG, the amount of medication was reduced.

The aim of the present study was to compare IOP reduction and inflammation after SLT treatment in primary open angle glaucoma (POAG) vs pseudoexfoliative glaucoma (PXFG) patients.

\section{Patients and methods Study design}

This was a prospective nonrandomized comparative study. A comprehensive medical and ocular history was obtained. All patients were asked about present inflammatory diseases and treatments. Ophthalmological examination was performed before including patients in the study. Visual acuity, IOP measurements, optic nerve status, gonioscopy, and the presence or absence of exfoliation were registered. Visual acuity was recorded using a Snellen's chart. IOP was measured using a Goldmann's applanation tonometer. The optic nerve status was then evaluated using a 90-D lens through an undilated pupil. Gonioscopy was performed in a darkroom using a goniolens with an undilated pupil and the anterior chamber angle was classified into 0-IV (according to Shaffer) and pigmentation was classified into $0-3 .{ }^{13}$ Pupils were dilated and exfoliation was checked; exfoliation was registered as present or absent. IOP, slit-lamp, and laser flare measurements were made before SLT and 2 hours, 1 week, and 1 month after SLT. All included patients had at least two reliable visual fields showing typical glaucoma visual field damage. Visual fields were checked using the Humphrey 24-2, SITA fast program (Carl Zeiss Meditec, Inc, Dublin, CA). For calculations, an average of the values of mean deviation (MD) and visual field index (VFI) were calculated using the two last visual fields.

The SLT is a Q-switched, frequency-doubled Nd:YAG, with a wavelength around $532 \mathrm{~nm}$. The SLT uses a single pulse (pulse duration $3 \mathrm{~ns}$ ) and the spot size is estimated to be $400 \mu \mathrm{m}$. In the present study, SLT treatment was performed over $90^{\circ}$ with the SLT Solo laser (Ellex, Australia) using some 25-30 spots applied to the trabecular meshwork. Traditionally, $180^{\circ}$ of the trabecular meshwork is treated, but a recent study ${ }^{14}$ has shown that $90^{\circ}$ treatment provides a similar effect. The initial energy used was $0.9 \mathrm{~mJ}$. The energy was increased or decreased until bubble formation appeared and was then decreased by $0.1 \mathrm{~mJ}$ for the remainder of the treatment. The energy used in the present study was in the range 0.9-1.1 mJ.

All patients continued with the same medical treatment after SLT. No patient was treated with corticoids, NSAIDs, or apraclonidine before or after SLT treatment.

Inflammation was measured using a laser flare meter Kowa FM-500 (Kowa Europe, Düsseldorf, Germany). The Kowa FM-500 is based on the measurement principle of detecting scattered laser light. The unit of measurement employed by the FM-500 is photon counts per millisecond ( $\mathrm{pc} / \mathrm{ms})$. A $1+$ seen in the slit-lamp corresponds to a laser flare photometry value of $28.3 \pm 4.8 \mathrm{pc} / \mathrm{ms}$ and a flare of $3+$ to a value of $82.5 \pm 5.2 \mathrm{pc} / \mathrm{ms}$ according to Guex-Crosier et al. ${ }^{15}$ Herbort et $\mathrm{al}^{16}$ have shown that even normal eyes express a normal flare measured to be $4 \mathrm{pc} / \mathrm{ms}$.

\section{Study population}

Patients presenting at the Glaucoma Department at the St Erik Eye Hospital for SLT treatment who fulfilled the inclusion criteria were asked to participate in the study. Patients were enrolled consecutively between January 2009 and December 2009.

Every patient provided informed consent to participate in the study and had ample opportunity to pose questions to the study's principal investigator. No direct rewards for participation or other incentives were given. The study was approved by the Ethical Committee at the Karolinska Institutet (approval number: 2009/1:1).

\section{Inclusion criteria}

- Patients suffering from POAG or PXFG who will be treated with SLT. All patients had at least two reliable visual fields (HFA, SITA fast) showing glaucoma damage.

- Gonioscopy: open angle defined as > grade II (Shaffer classification: scale $0-\mathrm{IV}$ ).

\section{Exclusion criteria}

- Patients treated with cortisone or immunosuppressive drugs.

- Patients suffering from ocular or systemic inflammatory diseases. 
- Patients who cannot be treated with SLT due to the eye's characteristics (shallow anterior chamber) or bad collaboration.

- Patients treated with pilocarpine (miosis makes laser flare measurements very difficult).

\section{Statistical considerations IOP}

The IOP was measured before treatment and 2 hours, 1 week, and 1 month after SLT in both the treated and the untreated eye. For statistical purposes, the authors considered the difference in IOP between the measurements made before treatment and 1 month after SLT in the treated eyes. A comparison was then made between the POAG and the PXFG groups using a double-tailed Student's $t$-test.

\section{Laser flare measurements}

The laser flare measurements were performed before SLT and 2 hours, 1 week, and 1 month after SLT. A double-tailed Student's $t$-test was performed to test significance in the POAG vs PXFG comparison, with a significance level of 5\%.

Sample size was estimated using STATA software (StataCorp, College Station, TX), with a power of 95\%. The sample size was estimated to be 26 patients in each group.

\section{Results}

Sixty patients (60 eyes) were included in the study. When both eyes were treated, one eye was chosen at random. All participants attended their appointments. The average age was 72.6 (SD 10.38) years. The gender distribution was $32 \mathrm{men} / 28$ women. Each group included 16 men and 14 women.

Regarding patient distribution, $\mathrm{n}=30$ pseudoexfoliative glaucoma, $n=30$ open angle glaucoma (two patients in the PXFG group were excluded at random to make both groups equal). Regarding the number of SLT procedures undergone, $\mathrm{n}=45$ were treated with SLT for the first time; $\mathrm{n}=8$ were treated for the second time; and $n=7$ were treated for the third time. All patients were treated with at least one kind of pressure-lowering eye drop (Table 1).

\section{Intraocular pressure}

The intraocular pressure reduction 1 month after SLT was $6.87 \mathrm{mmHg}$ in the POAG group and $6.19 \mathrm{mmHg}$ in the PXFG group. The $t$-test showed no significance ( $P=0.27$; Figure 1$)$.

\section{Inflammation}

Flare in the anterior chamber was measured at the four different time intervals: before SLT and 2 hours, 1 week, and
Table I Baseline characteristics of the subjects included in the study

\begin{tabular}{|c|c|c|c|}
\hline Characteristic & POAG & PXFG & $P$ value \\
\hline Age (years) (SD) & $71.60(12.44)$ & $75.47(8.17)$ & $>0.05$ \\
\hline $\begin{array}{l}\text { IOP before SLT } \\
(\mathrm{mmHg})(\mathrm{SD})\end{array}$ & $23.52(4.6)$ & $24.80(3.03)$ & $>0.05$ \\
\hline $\begin{array}{l}\text { Flare before SLT } \\
(\mathrm{pc} / \mathrm{ms})(\mathrm{SD})\end{array}$ & $7.18(3.08)$ & $8.98(4.8)$ & $>0.05$ \\
\hline $\begin{array}{l}\text { Average number of } \\
\text { spots per eye (SD) }\end{array}$ & $26.9(4.8)$ & $26.3(4.6)$ & $>0.05$ \\
\hline $\begin{array}{l}\text { Average dose per } \\
\text { eye (mJ) (SD) }\end{array}$ & $0.89(0.11)$ & $0.88(0.12)$ & $>0.05$ \\
\hline $\begin{array}{l}\text { Number of } \\
\text { medications (n) (SD) }\end{array}$ & $1.78(0.73)$ & $2.04(0.74)$ & $>0.05$ \\
\hline $\begin{array}{l}\text { Visual field MD } \\
\text { (dB) (SD) }\end{array}$ & $-18.1(7.54)$ & $-16.1(7.66)$ & $>0.05$ \\
\hline $\begin{array}{l}\text { Visual field VFI } \\
\text { (\%) (SD) }\end{array}$ & 45 (27.7) & $51.3(24.7)$ & $>0.05$ \\
\hline
\end{tabular}

Abbreviations: IOP, intraocular pressure; MD, mean deviation; POAG, primary open angle glaucoma; PXFG, pseudoexfoliative glaucoma; SD, standard deviation; SLT, selective laser trabeculoplasty; VFI, visual field index.

1 month after SLT in both the POAG group and the PXFG group. No significant difference in flare was found between the two groups at any of the time intervals tested: $(t$-test, before: $P=0.16$; 2 hours: $P=0.14$; 1 week: $P=0.12$; and 1 month: $P=0.36$; Figure 2 ).

\section{Discussion}

The present study showed no difference in IOP reduction and inflammation after SLT treatment when comparing POAG and PXFG. Scarce information was found regarding inflammation after SLT treatment. One of the first studies of SLT was that by Latina et al, ${ }^{17}$ who evaluated inflammation using the same device as that used in this study, the Kowa laser flare meter, and found significantly lower flare readings after SLT than ALT.

The absolute average (POAG + PXFG) flare values for treated eyes in our study after SLT treatment were around $8 \mathrm{pc} / \mathrm{ms}$. A $1+$ seen in the slit-lamp corresponds to a laser

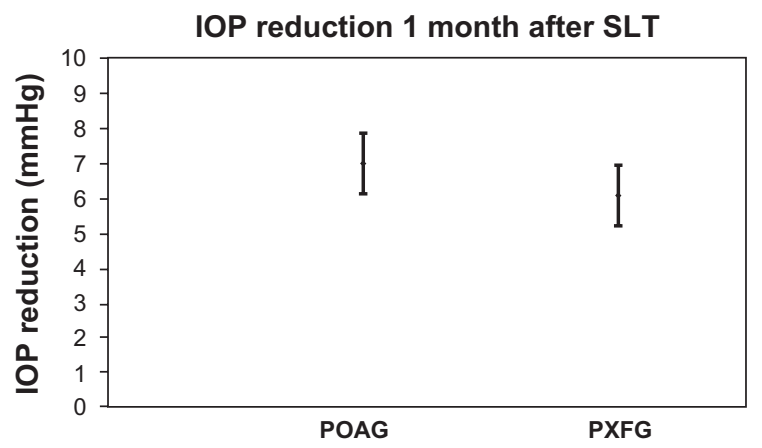

Figure I Intraocular pressure reduction comparing before and I month after SLT treatment, the bars represent $95 \%$ confidence interval for the mean.

Notes: $t$-test, $P=0.27$. 


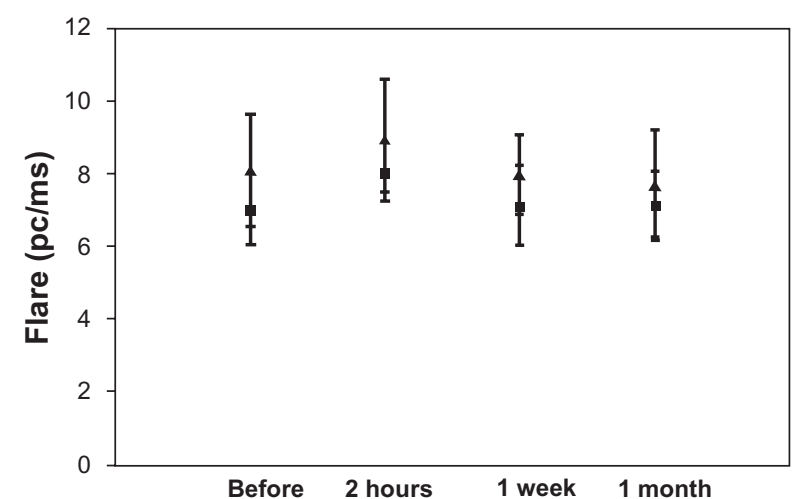

Figure 2 Flare measurements in both groups at different time intervals after SLT treatment.

Notes: The bars represent $95 \%$ confidence intervals for the mean. $(\boldsymbol{\Delta})$ represents the mean for the prostaglandin analogs group. ( $\mathbf{m})$ represents the mean for the nonprostaglandin analogs group. (t-test, before: $P=0.16 ; 2$ hours: $P=0.14$; I week: $P=0.12$, and I month: $P=0.36$ ).

flare photometry value of $28.3 \pm 4.8 \mathrm{pc} / \mathrm{ms}$ according to Guex-Crosier et al. ${ }^{15}$ SLT does not seem to induce clinically significant inflammation in our glaucoma patients. The study confirms previous results. ${ }^{18}$

Several studies into the effects of pseudoexfoliation in ALT treatment have been published. The overall results show quite a similar IOP reduction in POAG compared to PXFG. ${ }^{19-22}$ Threlkeld et $\mathrm{al}^{19}$ compared the effects of ALT in POAG vs PXFG and concluded that although the initial response to ALT in PXFG was greater, the long-term outcome (IOP reduction) in PXFG and POAG was similar.

With regard to the effects of SLT and pseudoexfoliation, the results of this study agree with Shazly et al, ${ }^{11}$ who found a similar IOP reduction in POAG and PXFG in a long-term study published recently.

One of the limitations of our study was the rather short follow-up time. Gracner ${ }^{10}$ reported no difference in IOP reduction after SLT treatment comparing POAG and PXFG (the author followed ten patients in each group over 18 months). The original purpose of the present study was to evaluate the inflammation following SLT treatment, so a longer follow-up would not provide any additional information. According to previous studies, ${ }^{17,23}$ inflammation decreases 1 month after SLT treatment. Furthermore, after this time, some patients from each group had their glaucoma medication discontinued or their SLT treatment repeated and this could have altered the results. Considering IOP, several studies have indicated that IOP remains stable at 6 months ${ }^{17}$ and 18 months. ${ }^{24}$ Therefore, the 1-month IOP values are likely to be predictive of future IOP control.

Another limitation could be selection bias. The St Erik Eye Hospital is a tertiary ophthalmic care institution, located in the centre of Stockholm, Sweden. The Glaucoma Department serves glaucoma patients from Stockholm County as well as from other counties. The Glaucoma Department takes care of the most complicated glaucoma cases. The POAG patients included in the study showed advanced glaucoma damage (MD: $-18 \mathrm{~dB}, \mathrm{VFI}: 45 \%$ ) and were perhaps not very representative of all POAG patients. It is possible that the results would have been different if patients with less visual field damage were included.

Pseudoexfoliation and pseudoexfoliative glaucoma are common findings among patients in Northern Europe. ${ }^{7}$ It was not difficult to recruit patients suffering from pseudoexfoliative glaucoma for our study, in part due to the high pseudoexfoliation prevalence in Sweden, but also due to the fact that pseudoexfoliative glaucoma usually requires additional therapy and SLT seems to be a good alternative. The energy used for SLT treatment in patients with pseudoexfoliation was the same as that used in patients without pseudoexfoliation. Pseudoexfoliation is often associated with increased pigmentation in the trabecular meshwork. In ALT treatment, it has been postulated that a greater IOP reduction in PXFG than in POAG is probably due to the greater degree of pigmentation. It is possible that the thermal effect of ALT is absorbed more at angles containing greater amounts of melanin. ${ }^{21}$

In conclusion, SLT effectively and safely lowers IOP in eyes with both POAG and PXFG. Pseudoexfoliation does not seem to be a risk factor for post-laser complications.

\section{Acknowledgments}

Supported in part by grants from the Karolinska Institutet's Foundation and the Signhild Engkvist Foundation.

\section{Disclosure}

The authors report no conflicts of interest in this work.

\section{References}

1. Leske MC, Heijl A, Hussein M, Bengtsson B, Hyman L, Komaroff E; Early Manifest Glaucoma Trial Group. Factors for glaucoma progression and the effect of treatment: the early manifest glaucoma trial. Arch Ophthalmol. 2003;121(1):48-56.

2. The Glaucoma Laser Trial Research Group. The Glaucoma Laser Trial (GLT). Results of argon laser trabeculoplasty versus topical medicines. Ophthalmology. 1990;97(11):1403-1413.

3. The Glaucoma Laser Trial Research Group. The Glaucoma Laser Trial (GLT) and glaucoma laser trial follow-up study: 7. Results. Am J Ophthalmol. 1995;120(6):718-731.

4. Lee R, Hutnik CM. Projected cost comparison of selective laser trabeculoplasty versus glaucoma medication in the Ontario Health Insurance Plan. Can J Ophthalmol. 2006;41(4):449-456.

5. Latina MA, Park C. Selective targeting of trabecular meshwork cells: in vitro studies of pulsed and CW laser interactions. Exp Eye Res. 1995; 60(4):359-371 
6. Karger RA, Jeng SM, Johnson DH, Hodge DO, Good MS. Estimated incidence of pseudoexfoliation syndrome and pseudoexfoliation glaucoma in Olmsted County, Minnesota. J Glaucoma. 2003;12(3): 193-197.

7. Aström S, Stenlund H, Lindén C. Incidence and prevalence of pseudoexfoliations and open-angle glaucoma in northern Sweden: II. Results after 21 years of follow-up. Acta Ophthalmol Scand. 2007;85(8):832-837.

8. Ringvold A. Epidemiology of glaucoma in northern Europe. Eur $J$ Ophthalmol. 1996;6(1):26-29.

9. Ekström C. Prevalence of open-angle glaucoma in central Sweden. The Tierp Glaucoma Survey. Acta Ophthalmol Scand. 1996;74(2): 107-112.

10. Gracner T. Intraocular pressure response of capsular glaucoma and primary open-angle glaucoma to selective Nd:YAG laser trabeculoplasty: a prospective, comparative clinical trial. Eur J Ophthalmol. 2002;12(4): 287-292.

11. Shazly TA, Smith J, Latina MA. Long-term safety and efficacy of selective laser trabeculoplasty as primary therapy for the treatment of pseudoexfoliation glaucoma compared with primary open-angle glaucoma. Clin Ophthalmol. 2010;5:5-10.

12. Goldenfeld M, Geyer O, Segev E, Kaplan-Messas A, Melamed S. Selective Laser Trabeculoplasty in Uncontrolled Pseudoexfoliation Glaucoma. Ophthalmic Surg Lasers Imaging. 2011:1-4. doi 10.3928/15428877-20110630-601.

13. Kanski J. Clinical Ophthalmology: A Systematic Approach. London, UK: Butterworth-Heinemann Ltd; 1990:187.

14. Chen E, Golchin S, Blomdahl S. A comparison between 90 degrees and 180 degrees selective laser trabeculoplasty. J Glaucoma. 2004;13(1): 62-65.

15. Guex-Crosier Y, Pittet N, Herbort CP. Sensitivity of laser flare photometry to monitor inflammation in uveitis of the posterior segment. Ophthalmology. 1995;102(4):613-621.
16. Herbort CP, Guex-Crosier Y, de Ancos E, Pittet N. Use of laser flare photometry to assess and monitor inflammation in uveitis. Ophthalmology. 1997;104(1):64-71; discussion 71-72.

17. Latina MA, Sibayan SA, Shin DH, Noecker RJ, Marcellino G. Q-switched 532-nm Nd:YAG laser trabeculoplasty (selective laser trabeculoplasty): a multicenter, pilot, clinical study. Ophthalmology. 1998;105(11):2082-2088; discussion 2089-2090.

18. Ayala M, Landau Högbeck I, Chen E. Inflammation assessment after selective laser trabeculoplasty (SLT) treatment. Acta Ophthalmol. 2011; 89(4): e306-e309.

19. Threlkeld AB, Hertzmark E, Sturm RT, Epstein DL, Allingham RR. Comparative study of the efficacy of argon laser trabeculoplasty for exfoliation and primary open-angle glaucoma. J Glaucoma. 1996;5(5): 311-316.

20. Tuulonen A, Airaksinen PJ. Laser trabeculoplasty I in simple and capsular glaucoma. Acta Ophthalmol (Copenh). 1983;61(6):1009-1015.

21. Higginbotham EJ, Richardson TM. Response of exfoliation glaucoma to laser trabeculoplasty. Br J Ophthalmol. 1986;70(11):837-839.

22. Bergeå B. Intraocular pressure reduction after argon laser trabeculoplasty in open-angle glaucoma. A two-year follow-up. Acta Ophthalmol (Copenh). 1986;64(4):401-406.

23. Martinez-de-la-Casa J, Garcia-Feijoo J, Castillo A, et al. Selective vs argon laser trabeculoplasty: hypotensive efficacy, anterior chamber inflammation, and postoperative pain. Eye (Lond). 2004;18 498-502.

24. Melamed S, Ben Simon GJ, Levkovitch-Verbin H. Selective laser trabeculoplasty as primary treatment for open-angle glaucoma: a prospective, nonrandomized pilot study. Arch Ophthalmol. 2003;121(7) 957-960.
Clinical Ophthalmology

\section{Publish your work in this journal}

Clinical Ophthalmology is an international, peer-reviewed journal covering all subspecialties within ophthalmology. Key topics include: Optometry; Visual science; Pharmacology and drug therapy in eye diseases; Basic Sciences; Primary and Secondary eye care; Patient Safety and Quality of Care Improvements. This journal is indexed on

Submit your manuscript here: http://www.dovepress.com/clinical-ophthalmology-journal

\section{Dovepress}

PubMed Central and CAS, and is the official journal of The Society of Clinical Ophthalmology (SCO). The manuscript management system is completely online and includes a very quick and fair peer-review system, which is all easy to use. Visit http://www.dovepress.com/ testimonials.php to read real quotes from published authors. 